Article

\title{
Presolvated Electron Reactions with Methyl Acetoacetate: Electron Localization, Proton-Deuteron Exchange, and H-Atom Abstraction
}

\author{
Alex Petrovici, Amitava Adhikary, Anil Kumar and Michael D. Sevilla * \\ Department of Chemistry, Oakland University, Rochester, MI 48309, USA; \\ E-Mails: aopetrov@oakland.edu (A.P.); adhikary@oakland.edu (A.A.); kumar@oakland.edu (A.K.) \\ * Author to whom correspondence should be addressed; E-Mail: sevilla@oakland.edu; \\ Tel.: +1-248-370-2328; Fax: +1-248-370-2321.
}

Received: 24 July 2014; in revised form: 22 August 2014 / Accepted: 25 August 2014 /

Published: 1 September 2014

\begin{abstract}
Radiation-produced electrons initiate various reaction processes that are important to radiation damage to biomolecules. In this work, the site of attachment of the prehydrated electrons with methyl acetoacetate $\left(\mathrm{MAA}, \mathrm{CH}_{3}-\mathrm{CO}-\mathrm{CH}_{2}-\mathrm{COOCH}_{3}\right)$ at $77 \mathrm{~K}$ and subsequent reactions of the anion radical $\left(\mathrm{CH}_{3}-\mathrm{CO} \cdot{ }^{-}-\mathrm{CH}_{2}-\mathrm{COOCH}_{3}\right)$ in the 77 to ca. $170 \mathrm{~K}$ temperature range have been investigated in homogeneous $\mathrm{H}_{2} \mathrm{O}$ and $\mathrm{D}_{2} \mathrm{O}$ aqueous glasses by electron spin resonance (ESR) spectroscopy. At $77 \mathrm{~K}$, the prehydrated electron attaches to MAA forming the anion radical in which the electron is delocalized over the two carbonyl groups. This species readily protonates to produce the protonated electron adduct radical $\mathrm{CH}_{3}-\mathrm{C}(\cdot) \mathrm{OH}-\mathrm{CH}_{2}-\mathrm{COOCH}_{3}$. The ESR spectrum of $\mathrm{CH}_{3}-\mathrm{C}(\cdot) \mathrm{OH}-\mathrm{CH}_{2}-\mathrm{COOCH}_{3}$ in $\mathrm{H}_{2} \mathrm{O}$ shows line components due to proton hyperfine couplings of the methyl and methylene groups. Whereas, the ESR spectrum of $\mathrm{CH}_{3}-\mathrm{C}(\cdot) \mathrm{OH}-\mathrm{CH}_{2}-\mathrm{COOCH}_{3}$ in $\mathrm{D}_{2} \mathrm{O}$ glass shows only the line components due to proton hyperfine couplings of $\mathrm{CH}_{3}$ group. This is expected since the methylene protons in MAA are readily exchangeable in $\mathrm{D}_{2} \mathrm{O}$. On stepwise annealing to higher temperatures ( $c$ a. 150 to $170 \mathrm{~K}$ ), $\mathrm{CH}_{3}-\mathrm{C}(\cdot) \mathrm{OH}-\mathrm{CH}_{2}-\mathrm{COOCH}_{3}$ undergoes bimolecular $\mathrm{H}$-atom abstraction from MAA to form the more stable radical, $\mathrm{CH}_{3}-\mathrm{CO}-\mathrm{CH} \cdot-\mathrm{COOCH}_{3}$. Theoretical calculations using density functional theory (DFT) support the radical assignments.
\end{abstract}

Keywords: prehydrated electron; anion radical; proton-deuteron exchange; H-atom abstraction 


\section{Introduction}

Ionizing radiation transfers energy to matter by the production of holes, ejected electrons, and excited states [1]. Of these, the holes have been considered to be the most damaging [1]. However, in the last few years, electrons, especially low energy electrons (LEEs), have been recognized as a major contributor to radiation damage [2,3]. LEEs are simply electrons having energies in the range of 0-20 eV which can cause damage by inducing bond cleavage via dissociative electron attachment (DEA) [2,3]. In aqueous solution, the LEEs that do not react by DEA, undergo thermal deactivation and lead to the formation of solvated electrons $\left(\mathrm{e}_{\mathrm{aq}}{ }^{-}\right)$[2,3]. $\mathrm{e}_{\mathrm{aq}}{ }^{-}$add to the electron affinic sites in molecules and induce reactions that follow adiabatic pathways [3].

Electrons formed in irradiated $\mathrm{LiCl}$ aqueous glasses are predominantly trapped in shallow wells [4]. The most abundant trapped electron species is $c a .0 .5 \mathrm{eV}$ below the continuum, although some traps can be as deep as $2.6 \mathrm{eV}$ [4]. Since electrons react with the solutes prior to complete solvation, the reactions of electrons in these irradiated glasses are primarily due to these partially solvated electrons which are known as presolvated (prehydrated) electrons ( $\mathrm{e}_{\mathrm{pre}}{ }^{-}$) [5-7].

For many molecular systems with functional groups that can capture electrons such as ketones, esters, carboxylic acids, and peptides, it is well known that the anion radicals formed on $\mathrm{e}_{\mathrm{pre}}{ }^{-}$addition undergo subsequent reactions [8-11]. For peptides, the most common reaction of the anion radical is either deamination or deamidation. For ketones and esters, the anion radicals formed on electron attachment lead to reactive intermediates that may undergo bimolecular H-atom abstraction reactions. This is shown below for acetone anion radical, $\mathrm{p} K_{\mathrm{a}}=c a .12$ [12] (Scheme 1, reaction (1)), which after protonation (Scheme 1, reaction (2)) produces a neutral C-centered radical; this radical can undergo bimolecular $\mathrm{H}$-atom abstraction from a weak $\mathrm{C}-\mathrm{H}$ bond to form isopropyl alcohol (Scheme 1, reaction (3)) [8].

Scheme 1. Reactions intiated by presolvated electron attachment to acetone.

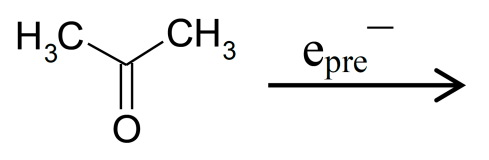<smiles>CC(C)[O-]</smiles>

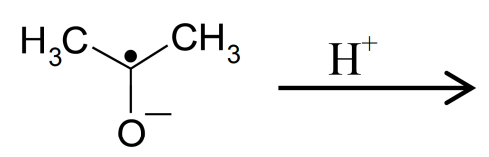<smiles>CC(C)O</smiles>

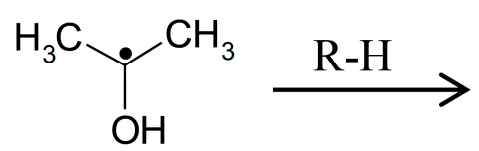<smiles>[R][CH]C(C)(C)O</smiles>

Or, for esters, O-C bond cleavage reactions (Scheme 2, reactions $(4,5)$ ) by DEA in the anion radical formed after the addition of the prehydrated electron $\left(\mathrm{e}_{\mathrm{pre}}{ }^{-}\right)$to the carbonyl group, are observed frequently [9], such as: 
Scheme 2. Reactions initiated by presolvated electron attachment to methyl acetate.<smiles>COC(C)=O</smiles><smiles>[CH2-][C@H]([O-])OC(C)=O</smiles>

In the current study, we have investigated prehydrated electron attachment to methyl acetoacetate (MAA) in homogeneous aqueous $\left(\mathrm{H}_{2} \mathrm{O}\right.$ or $\left.\mathrm{D}_{2} \mathrm{O}\right)$ glasses at $77 \mathrm{~K}$ and followed the subsequent reactions of the MAA anion radical in the 77 to $c a$. $170 \mathrm{~K}$ temperature range employing electron spin resonance (ESR) spectroscopy and density functional theory (DFT). We note that irradiation of $7.5 \mathrm{M} \mathrm{LiCl}$ aqueous glasses at $77 \mathrm{~K}$ produces only two intermediates: prehydrated electrons and $\mathrm{Cl}_{2}{ }^{-}[10,13,14]$. In our system $\mathrm{Cl}_{2}{ }^{-}$is unable to one-electron oxidize simple aliphatic ketones or esters and thus does not interfere with the study of the reactions of prehydrated electron [10]. The combination of experimental and theoretical results clearly shows that in MAA the initial localization of the electron is chiefly at the carbonyl site and that protonation of the carbonyl group further localizes the electron to this site. The protonated MAA anion radical is found to undergo bimolecular $\mathrm{H}$-atom abstraction from the parent compound (i.e., MAA).

\section{Results and Discussion}

\subsection{ESR Studies in $\mathrm{H}_{2} \mathrm{O}$}

In Figure 1, the ESR spectra found after $\gamma$-irradiation (600 Gy) at $77 \mathrm{~K}$ of a sample of MAA in $7.5 \mathrm{M}$ $\mathrm{LiCl}$ in $\mathrm{H}_{2} \mathrm{O}$ are shown. The black spectrum in Figure 1A resulting from electron attachment to MAA clearly shows a six line multiplet which is assigned to three $c a .18 \mathrm{G}$ proton hyperfine couplings from a methyl group and a single proton coupling of $c a .37 \mathrm{G}$ from one of the methylene group protons. The experimental spectrum (black) has been simulated using four lines of equal intensity separated by $18 \mathrm{G}$ to account for the methyl proton hyperfine couplings, a single proton hyperfine coupling of $37 \mathrm{G}$, g-value $=2.0029$, and a mixed $(($ Lorentzian $/$ Gaussian $)=0.2)$ line-width $=8 \mathrm{G}$. The simulated spectrum (pink) has been superimposed on the experimental spectrum for comparison. This spectrum is assigned to radical II formed after protonation of the anion radical, reactions 6 and 7. The line intensities of the methyl protons are close to $1: 1: 1: 1$ rather than the expected 1:3:3:1 line intensities owing to the well-known tunneling rotation of the methyl groups at $77 \mathrm{~K}$ [15]. Such restricted rotation of methyl group is expected at low temperatures and has been observed after electron addition to $\mathrm{CH}_{3} \mathrm{CO}$ - groups such as in acetic acid, acetamide and $\mathrm{N}$-acetylmethionine at $77 \mathrm{~K}[11,15,16]$. These anion radicals exhibit the normal and expected 1:3:3:1 line intensity ratios of the methyl protons at higher temperatures (provided the anion radicals are stable at that elevated temperature [15]. Hyperfine couplings from both the methyl group and the methylene in spectrum 1A show that the electron addition is to the carbonyl group at $77 \mathrm{~K}$. No evidence is found for electron addition to the acetate linkage of MAA even though esters are known to readily form anion radicals at low temperatures [9]. 
The trapping of the electron at the carbonyl group in MAA at $77 \mathrm{~K}$ might suggest that the carbonyl group in MAA has a higher electron affinity than its acetate moiety. However, DFT calculations presented here (Section 2.3) show that it is the protonation of the carbonyl oxygen in MAA that helps to localize the electron to the carbonyl group.

Figure 1. ESR spectra of the prehydrated electron addition to MAA at $77 \mathrm{~K}$ and subsequent reactions of the MAA anion radical on annealing to $165 \mathrm{~K}$ in a $7.5 \mathrm{M} \mathrm{LiCl} \mathrm{H} \mathrm{H}_{2} \mathrm{O}$ glass. (A) The black spectrum of the protonated MAA anion radical (radical II). The pink spectrum is the simulated spectrum of radical II. For simulation parameters, see text; (B) Radical II, after conformational rearrangement; (C) Radical III, $\mathrm{CH}_{3}-\mathrm{CO}-\mathrm{C} \cdot \mathrm{H}-\mathrm{CO}-\mathrm{OCH}_{3}$, formed by $\mathrm{H}$-atom abstraction from the parent MAA molecule by radical II at $165 \mathrm{~K}$. The three reference markers (open triangles) in this figure and in the subsequent figures show the position of Fremy's salt resonance with the central marker at $g=2.0056$. Each of these markers is separated from each other by $13.09 \mathrm{G}$.

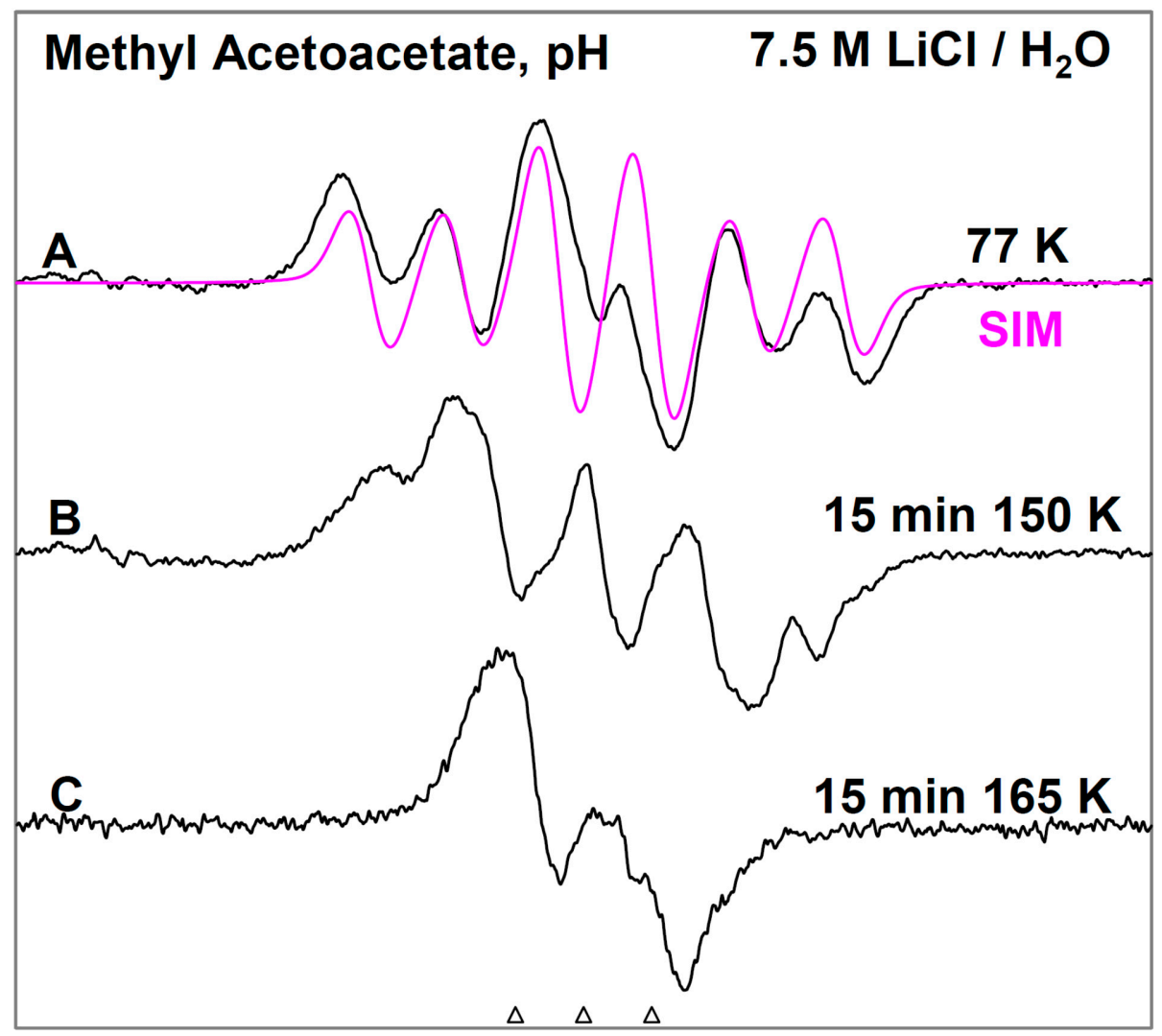

From the $\mathrm{p} K_{\mathrm{a}}$ of the acetone anion radical, $\mathrm{p} K_{\mathrm{a}}=c a .12$ [12], it is expected that the anion of carbonyl group in MAA anion radical has a $\mathrm{p} K_{\mathrm{a}}$ less than 12 owing to delocalization of spin and charge (see Section 2.3). Thus, the carbonyl group of the MAA anion radical is expected to be protonated on warming; however, DFT calculations suggest that protonation has occurred even at $77 \mathrm{~K}$ and hence, we have assigned spectrum $1 \mathrm{~A}$ to radical II.

On annealing from $77 \mathrm{~K}$ (spectrum 1A) to $150 \mathrm{~K}$ (spectrum 1B), we find that the spectrum changes substantially. Note that all spectra are recorded at $77 \mathrm{~K}$ after annealing at each temperature. The broad lines in Figure 1B make the spectral analyses difficult. However, it appears that in spectrum 1B, the 
methylene proton coupling drops from $c a .37 \mathrm{G}$ to $c a .25 \mathrm{G}$ (Table 1). Upon increasing the temperature from 77 to $150 \mathrm{~K}$, the methylene protons likely take on a range of values that somewhat broaden the spectrum in Figure 1B. However, the methyl protons hyperfine couplings remain at $18 \mathrm{G}$ (see spectrum 2B). These results are suggestive of a further change in the conformation of radical II on annealing from $77 \mathrm{~K}$ to $150 \mathrm{~K}$. On this basis, spectrum $1 \mathrm{~B}$ is assigned to the conformationally rearranged radical II (Scheme 3, reaction (7)).

Table 1. DFT Calculated Proton hyperfine couplings (B3LYP/6-31G*).

\begin{tabular}{|c|c|c|c|c|}
\hline \multirow[t]{2}{*}{ Radical } & \multirow[t]{2}{*}{ Phase } & \multicolumn{3}{|c|}{ Proton Hyperfine Couplings ${ }^{1,2}$ (Gauss) } \\
\hline & & $\mathrm{CH}_{3}$ & $\mathrm{CH}_{2}$ & O-H $[x x, y y, z z]^{1}$ \\
\hline \multirow{2}{*}{ I (opt) } & vacuum & 11.6 & $18.7,6.6$ & $\begin{array}{ll}- \\
-\end{array}$ \\
\hline & PCM & 13.1 & $25.4,4.9$ & - \\
\hline \multirow{2}{*}{ II (opt) } & vacuum & 18.5 & $35.6,0.8$ & {$[-6.5,-5.5,5.4]$} \\
\hline & PCM & 18.7 & $35.9,0.9$ & {$[-6.7,-5.7,5.0]$} \\
\hline II (Exp) & Glass $^{3}$ & 18 & $37,<5$ & unresolved \\
\hline \multirow[t]{2}{*}{ III (opt) } & \multicolumn{3}{|c|}{ C-H [xx, yy, zz] } & - \\
\hline & PCM & \multirow{2}{*}{\multicolumn{2}{|c|}{$\begin{array}{c}{[-29.6,-20.9,-8.0]} \\
c a .-22\end{array}$}} & - \\
\hline III (Exp) & Glass $^{3}$ & & & - \\
\hline
\end{tabular}

${ }^{1}$ Hyperfine couplings are isotropic values except for those in brackets which are the sum of isotropic and anisotropic values; opt $=$ geometry optimized; ${ }^{2}$ Proton couplings for the methyl and methylene protons are $\beta$-proton couplings and have only small anisotropic components. Thus only the isotropic values are given; ${ }^{3}$ Glass $=7.5 \mathrm{M} \mathrm{LiCl} / \mathrm{H}_{2} \mathrm{O}$.

Scheme 3. Reactions initiated by presolvated electron attachment to MAA.<smiles>COC(=O)CC(C)=O</smiles><smiles>CC#CC</smiles><smiles>COC(=O)C=C(C)O</smiles><smiles>COC(=O)[CH]C(C)=O</smiles><smiles>C[CH+]C</smiles>

Radical I<smiles>COC(=O)C[C@@H](C)O</smiles>

Radical II<smiles>COC(=O)CC(C)O</smiles><smiles>CC1CCCC1C</smiles><smiles>[R4]C(Cl)=C([R4])[C@@H](C(C)=O)C(=O)OC</smiles>

On annealing to $165 \mathrm{~K}$ (Figure 1C), we find that a ca. $22 \mathrm{G}$ doublet (Table 1) builds in with the loss of the signal of the protonated electron adduct radical (II). This species is assigned to the radical (III) $\left(\mathrm{CH}_{3}-\mathrm{CO}-\mathrm{CH} \cdot-\mathrm{COOCH}_{3}\right)$ formed by the biomolecular $\mathrm{H}$-atom abstraction of a methylene proton of the parent MAA molecule by the radical II (Scheme 3, reaction (8)). 


\subsection{ESR Studies in $\mathrm{D}_{2} \mathrm{O}$}

Our results in $\mathrm{D}_{2} \mathrm{O}$ glasses, for otherwise identical (i.e., matched) samples clarify and add strong support for the above analyses (Scheme 3, reactions (6) to (8)). Owing to the $\mathrm{p} K_{\mathrm{a}}$ of $-\mathrm{CH}_{2}$ group of MAA as 11 [17] and $\mathrm{pD}$ of the $7.5 \mathrm{M} \mathrm{LiCl} / \mathrm{D}_{2} \mathrm{O}$ solution being $c a .5$ [18], the $\mathrm{CH}_{2}$ group in MAA has undergone complete deuterium exchange in $\mathrm{D}_{2} \mathrm{O}$ solutions of $7.5 \mathrm{M} \mathrm{LiCl}$ i.e., MAA is converted to $\mathrm{CH}_{3}-\mathrm{CO}-\mathrm{CD}_{2}-\mathrm{COOCH}_{3}$ in $7.5 \mathrm{M} \mathrm{LiCl} / \mathrm{D}_{2} \mathrm{O}$.

In Figure 2, the results in $\mathrm{D}_{2} \mathrm{O}$ glasses are shown. At $77 \mathrm{~K}$, only four major lines expected from the methyl group hyperfine couplings $(c a .18 \mathrm{G}$ ) are observed in spectrum 2A. Owing to the smaller magnetic moment of deuterons than protons, deuterons show hyperfine couplings that are only $15 \%$ $(1 / 6.514)$ that of protons in the same environment [18-20]. Hence, the one methylene proton coupling of $c a .37 \mathrm{G}$, is reduced to $5.7 \mathrm{G}$ deuterium coupling. Also any unresolved couplings from the other remaining methylene proton and the hyperfine coupling due to $-\mathrm{OH}$ in radical II (Scheme 3, reaction (7)) are lost as expected since they are now deuterons in $\mathrm{CH}_{3}-\mathrm{C} \cdot \mathrm{OD}-\mathrm{CD}_{2}-\mathrm{COOCH}_{3}$. Analyses of the central two lines in Figure $2 \mathrm{~A}(77 \mathrm{~K})$ do show a poorly resolved triplet (marked with lines) of $5.7 \mathrm{G}$ as expected. Therefore, spectrum $2 \mathrm{~A}$ is assigned to $\mathrm{CH}_{3}-\mathrm{C} \cdot \mathrm{OD}-\mathrm{CD}_{2}-\mathrm{COOCH}_{3}$.

Figure 2. ESR spectra of prehydrated electron addition to MAA and subsequent reactions of the MAA anion radical on annealing to $170 \mathrm{~K}$ in a $7.5 \mathrm{M} \mathrm{LiCl} / \mathrm{D}_{2} \mathrm{O}$ glass. (A) The deuterated electron adduct, radical II. Note the central components show distinct deuterium couplings of the exchanged methylene deuteron (marked with hash marks); (B) Deuterated radical II after conformational rearrangement in which the deuterium couplings are lost; (C) Gradual formation of deuterated radical III as radical II is lost; (D) Deuterated radical III, $\mathrm{CH}_{3}-\mathrm{CO}-\mathrm{C} \cdot \mathrm{D}-\mathrm{COOCH}_{3}$, formed by hydrogen (deuteron) abstraction from the parent molecule by II at $170 \mathrm{~K}$.

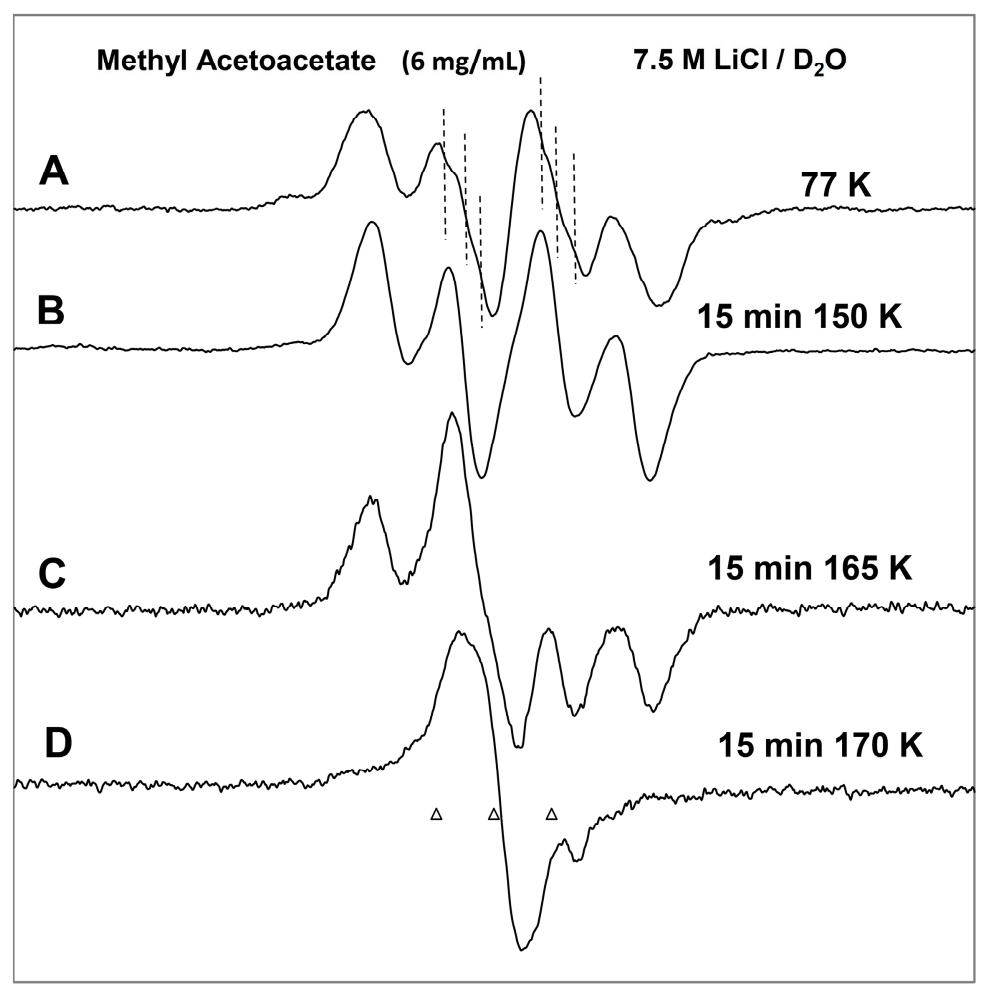


On annealing to $150 \mathrm{~K}$, this poorly resolved triplet is lost in spectrum $2 \mathrm{~B}$ which is expected since the rearrangement found in $\mathrm{H}_{2} \mathrm{O}$ at this temperature suggests only a $3.8 \mathrm{G}$ deuteron coupling will be observed from the methylene, i.e., $25 / 6.514 \mathrm{G}$ and this is too small to observe. However, the methyl proton hyperfine coupling remains at $c a .18 \mathrm{G}$ in $\mathrm{D}_{2} \mathrm{O}$ as it was in $\mathrm{H}_{2} \mathrm{O}$ glasses.

On annealing to higher temperatures, $165 \mathrm{~K}$ (Figure 2C) and then to $170 \mathrm{~K}$ (Figure 2D), a singlet gradually builds in with the loss of the signal of four line spectrum of the deuterated radical II. This species is assigned to the deuterated radical III (reaction 8), i.e., $\mathrm{CH}_{3}-\mathrm{CO}-\mathrm{CD} \cdot-\mathrm{COOCH}_{3}$, formed by deuterium atom abstraction from the deuterated methylene of the parent MAA (Scheme 3, reaction (8)). Comparison of Figure $1 \mathrm{C}\left(\mathrm{H}_{2} \mathrm{O}\right)$ with Figure $2 \mathrm{C}\left(\mathrm{D}_{2} \mathrm{O}\right)$ clearly shows that reaction (8) takes place more slowly in $\mathrm{D}_{2} \mathrm{O}$ over that found in $\mathrm{H}_{2} \mathrm{O}$. This kinetic isotope effect is expected because a $\mathrm{C}$-D bond is $c a .1 \mathrm{kcal} / \mathrm{mole}$ stronger than a $\mathrm{C}-\mathrm{H}$ bond simply from vibrational zero point energy considerations [21].

In summary, the overall experimental results shown in Figures 1 and 2 strongly support the following mechanism: prehydrated electron addition to the carbonyl group in MAA (Scheme 3, reaction (6)) which is followed by protonation of the electron adduct of MAA at $77 \mathrm{~K}$ (reaction 7) and the subsequent $\mathrm{H}$-atom abstraction from the parent MAA by the protonated electron adduct (Scheme 3, reaction (8)).

The effect of $\mathrm{pH}$ has also been investigated in identically prepared samples in $7.5 \mathrm{M} \mathrm{LiCl} / \mathrm{H}_{2} \mathrm{O}$ glasses but at $\mathrm{pH} c a$. 8.5. The initial spectrum found at $77 \mathrm{~K}$ after the prehydrated electron addition shows the identical spectrum of the protonated electron adduct (II) found at $\mathrm{pH} 5$. On annealing to $165 \mathrm{~K}$, similar to the spectrum $1 \mathrm{C}$, the $c a$. $22 \mathrm{G}$ doublet is formed. Thus, the mechanism shown in reactions (6) to (8) is not affected by increasing the $\mathrm{pH}$ from $c a$. 5 to $c a$. 8.5.

\subsection{DFT Calculations}

DFT calculations for each of radical intermediates (I, II, and III) have been performed using the B3LYP functional and a $6-31 \mathrm{G}^{*}$ basis set. The DFT/B3LYP/6-31G* method is known to provide hyperfine couplings that are in excellent agreement with the experimentally obtained ones $[1,13,14,18,19,22]$. In our calculations, the solvent has been treated by use of the polarized continuum model (PCM) as implemented in Gaussian 09 [23]. The geometry of each of the radicals has been optimized employing the DFT/B3LYP/6-31G* method and the hyperfine coupling constant values for each optimized radical intermediate were calculated. These theoretically calculated hyperfine coupling constants along with the corresponding experimentally obtained ones are shown in Table 1.

In radical I, the carbonyl group is not protonated and the isotropic hyperfine couplings of the $\beta$-protons of the methyl group and the methylene group are found to be significantly smaller than those obtained by experiment (Table 1). For the optimized protonated radical II, the isotropic hyperfine couplings are quite close to those found experimentally (Table 1: $18.7 \mathrm{G}$ (PCM) vs. $18 \mathrm{G}$ (experimental) and $35.9 \mathrm{G}$ (PCM) vs. $37 \mathrm{G}$ (experimental)).

The poor fit of the theoretically predicted hyperfine coupling constant values of the anion radical (I) with the experimentally obtained ones and the excellent fit of the protonated radical (II) with experiment indicates that the carbonyl functional group protonates even at low temperatures in the glassy system. Calculations employing PCM do alter hyperfine couplings of the anion radical (I) 
marginally but have a negligible effect on hyperfine couplings of the protonated radical (II) (Table 1). The protonated carbonyl is predicted to show anisotropic proton hyperfine couplings but of a magnitude that would simply broaden the line components in the ESR spectra somewhat and this is in agreement with experiment (Section 2.1 and Figure 1).

For the final radical III, the only ca. $22 \mathrm{G}$ doublet from the methylene $\alpha$-proton is observed. The calculation provides a typical anisotropic proton coupling tensor with a $c a .21 \mathrm{G}$ middle component that is in excellent agreement with the experimentally obtained overall value (Table 1, Figure 1). The spin density distributions in the three radicals found in this work are shown in Figure 3. They clearly show that on protonation of radical I to radical II, the unpaired spin localizes on the carbonyl group and substantially increases the interaction with the methyl group as indicated by the hyperfine couplings in Table 1. The final radical III shows the expected spin localization at the methylene carbon radical site.

Figure 3. The spin density distributions of radicals I, II and III are shown above the optimized structure of each radical. Note that protonation of the oxygen at the carbonyl group of radical I substantially localizes the spin at the carbonyl group in radical II and increases the coupling to the methyl protons. Only a fixed methyl group is shown with spin density largely on one methyl proton, however, experimentally the methyl group rotates and averages the spin over the three protons.

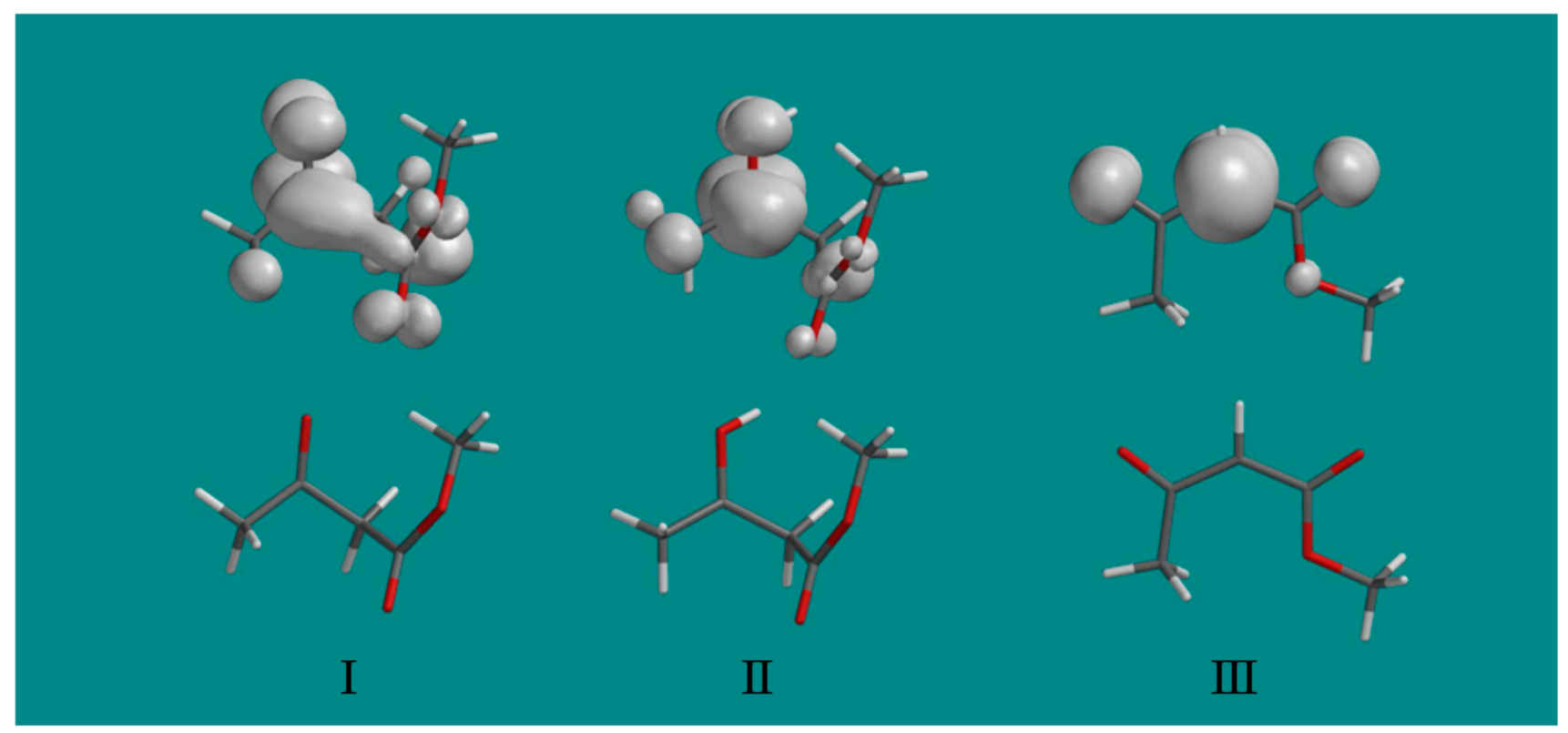

\section{Experimental Section}

\subsection{Materials}

Methyl acetoacetate and deuterium oxide $\left(\mathrm{D}_{2} \mathrm{O}\right)(99.9$ atom \% D) were purchased from Sigma-Aldrich (St. Louis, MO, USA). Lithium chloride ( $\mathrm{LiCl}$, ultra dry, 99.995\% (metals basis)) was obtained from Alfa Aesar (Ward Hill, MA, USA). Suprasil quartz tubes (4 mm OD, Catalog No. 734-PQ-8, Wilmad Glass Co., Inc., Buena, NJ, USA) were used for preparation of samples. 


\subsection{Sample Preparation}

Approximately 6 milligrams $(50 \mathrm{mM})$ of solute was dissolved in $7.5 \mathrm{M} \mathrm{LiCl}$ in $\mathrm{H}_{2} \mathrm{O}$ or $\mathrm{D}_{2} \mathrm{O}$ $(1.0 \mathrm{~mL})$. After the solute is fully dissolved, the solution has been bubbled with nitrogen gas for $5 \mathrm{~min}$ to remove oxygen from the samples. Subsequently, the solution is drawn into a $4 \mathrm{~mm}$ quartz tube and rapidly cooled to $77 \mathrm{~K}$ in liquid nitrogen to form a clear transparent glass as in our earlier works [8-11,13-16,18-20].

\subsection{Gamma Irradiation}

Gamma irradiations were performed with a GR-9 (Co-60) irradiator (dose rate $=0.5 \mathrm{kGy} / \mathrm{h}$, absorbed dose $=600 \mathrm{~Gy}$ ). All samples have been irradiated at $77 \mathrm{~K}$ in Teflon containers in the dark as well as are stored in these containers in the dark.

\subsection{ESR Studies}

Following our earlier studies, immediately after $\gamma$-irradiation of the glassy sample at $77 \mathrm{~K}$, its ESR spectrum is recorded at $77 \mathrm{~K}$. Also, immediately after each annealing step, the sample is cooled to $77 \mathrm{~K}$ by its immersion in liquid nitrogen $(77 \mathrm{~K})$ and its ESR spectrum is recorded at $77 \mathrm{~K}$ which maximizes signal height and allows for comparison of signal intensities. A Century Series X-band $(9.3 \mathrm{GHz}) \mathrm{ESR}$ spectrometer (Varian, Palo Alto, CA, USA) with an E-4531 dual cavity, 9-inch magnet, and a $200 \mathrm{~mW}$ Klystron has been used. Fremy's salt $\left(g_{\text {center }}=2.0056, A(\mathrm{~N})=13.09 \mathrm{G}\right)$ has been employed for the field calibration. All ESR spectra have been recorded at $77 \mathrm{~K}$ and at $45 \mathrm{~dB}(6.3 \mu \mathrm{W})$.

\subsection{Annealing of Glassy Samples and Radical Formation}

Irradiation of the sample produces only prehydrated electrons and $\mathrm{Cl}_{2}{ }^{-}[10,13,14]$. Since only electrons are mobile at $77 \mathrm{~K}$, all solute radicals at $77 \mathrm{~K}$ are formed due to the prehydrated electron attachment to the solute. A variable temperature assembly has been employed which passed liquid nitrogen cooled nitrogen gas past a thermister and over the sample as described in our earlier studies. Annealing of the sample at temperatures of $140 \mathrm{~K}-170 \mathrm{~K}$ allows for molecular migration as the glass softens and the stepwise observation of thermally induced radical reactions of the electron adducts. At these temperatures, $\mathrm{Cl}_{2}{ }^{-}$also becomes mobile but is not able to oxidize the solutes chosen for this study [10]. Thus, only solute anion radicals originating from prehydrated electron attachment and the subsequent reactions of these anion radicals are investigated in this work.

\subsection{DFT Calculations}

DFT calculations were performed using B3LYP and the 6-31G* basis set which is known to provide good estimates of hyperfine couplings [1,14,18,19,22]. All geometries were fully optimized. In our calculations, the solvent has been treated by use of the integral equation formalism polarized continuum model (IEF-PCM) as implemented in Gaussian 09 [23]. Calculations were performed using the Gaussian 09 program set [23]. The spin densities in the radicals have been obtained employing the Spartan'10 program set [24] at the B3LYP/6-31G*//B3LYP/6-31G* level theory in the gas phase. 


\section{Conclusions}

This work leads to the following salient conclusions:

(i) In MAA, the added electron localizes at the carbonyl group:

The combination of ESR and DFT calculations presented in this work clearly shows that in a molecule with a carbonyl and ester functionality separated by a methylene bridge, the site of prehydrated electron attachment is preferentially at the carbonyl group. However, the spin density distribution of the initial anion radical shows the spin is actually shared between the two sites with increased localization at the carbonyl occurring on protonation of the carbonyl oxygen. Thus, the difference in electron affinity (EA) of the two sites is not likely to be high but the greater $\mathrm{p} K_{\mathrm{a}}$ of the carbonyl site in the MAA anion radical favors the localization of the electron at that site.

(ii) Prehydrated electron-induced $\mathrm{CH}_{3}-\mathrm{O}$ bond cleavage is not observed in MAA:

Our previous work showed that prehydrated electron addition to methyl acetate at $77 \mathrm{~K}$ initiated dissociative electron attachment (DEA) that resulted in $\mathrm{CH}_{3}$ by $\mathrm{C}-\mathrm{O}$ bond cleavage, reaction (5) [9]. Our recent work with peptide methyl esters such as N-acetylalanylalanine methyl ester [10], prehydrated electron addition also results in $\mathrm{CH}_{3} \bullet$ formation at $77 \mathrm{~K}$ by $\mathrm{C}-\mathrm{O}$ bond cleavage (DEA) at $77 \mathrm{~K}$. Electron attachment in the latter species can be at any of three sites which are each localized species. However, only the attachment to the ester site induces $\mathrm{CH}_{3} \bullet$ formation. In this work we find that in MAA, a molecule with a carbonyl and ester functionality separated by a methylene bridge, the prehydrated electron attachment is at both groups as they form a delocalized spin system that localizes only on protonation of the carbonyl oxygen (Figure 3). The added delocalization protects MAA from DEA and formation of $\mathrm{CH}_{3} \bullet$.

(iii) The protonated anion radical of MAA is a H-atom abstraction agent:

This protonated radical (radical II) is found to be a hydrogen abstracting agent as in similar molecules [8,9] and selects the weak methylene $\mathrm{C}-\mathrm{H}$ bond for abstraction resulting in radical III. Radical III is expected to dimerize.

\section{Acknowledgments}

We thank the National Cancer Institute of the National Institutes of Health (Grant RO1CA045424) for support.

\section{Author Contributions}

AP an undergraduate student performed the experiments with the aid and supervision of AA. AK performed the DFT calculations. MDS gave overall direction, interpreted the data; MDS and AA wrote the manuscript.

\section{Conflicts of Interest}

The authors declare no conflict of interest. 


\section{References}

1. Becker, D.; Adhikary, A.; Sevilla, M.D. Physicochemical mechanisms of radiation induced DNA damage (Chapter 20). In Charged Particle and Photon Interactions with Matter, Recent Advances, Applications, and Interfaces; Hatano, Y., Katsumura, Y., Mozumder, A., Eds.; CRC Press, Taylor \& Francis: Boca Raton, FL, USA, 2010; pp. 503-541.

2. Sanche, L. Low energy electron-driven damage in biomolecules. Eur. Phys. J. D 2005, 35, 367-390.

3. Kumar A.; Sevilla, M.D. Low energy electron (LEE) induced DNA damage: Theoretical approaches to modeling experiment. In Biomolecules in Handbook of Computational Chemistry; Shukla, M., Leszczynski, J., Eds.; Springer: Heidelberg, Germany, 2012; pp. 1215-1256.

4. Gillis, H.A.; Teather, G.G.; Buxton, G.V. Pulse radiolysis of deuterated aqueous LiCl glasses. Dependence of the yields and rates of reaction of visible and infrared absorbing trapped electrons on $\mathrm{LiCl}$ concentration. Can. J. Chem. 1978, 56, 1889-1889.

5. Wolff, R.K.; Aldrich, J.E.; Penner, T.L.; Hunt, J.W. Picosecond pulse radiolysis. V. Yield of electrons in irradiated aqueous solution with high concentrations of scavenger. J. Phys. Chem. 1975, 79, 210-219.

6. Bartels, D.M.; Gosztola, D.; Jonah, C.D. Spur decay kinetics of the solvated electron in heavy water radiolysis. J. Phys. Chem. A 2001, 105, 8069-8072.

7. Lu, Q.-B.; Baskin, J.S.; Zewail, A.H. The presolvated electron in water: Can it be scavenged at long range? J. Phys. Chem. B 2004, 108, 10509-10514.

8. Sevilla, M.D.; Morehouse, K.M.; Swarts, S. An ESR study of electron reactions with carboxylic acids, ketones, and aldehydes in aqueous glasses. J. Phys. Chem. 1981, 85, 918-923.

9. Sevilla, M.D.; Swarts, S.; Bearden, R.; Morehouse, K.M.; Vartanian, T. ESR study of electron reactions with esters and triglycerides. J. Phys. Chem. 1981, 85, 923-927.

10. Kheir, J.F.; Chomicz, L.; Engle, A.M.; Rak, J.; Sevilla, M.D. Presolvated low energy electron attachment to peptide methyl esters in aqueous solution: CO bond cleavage at $77 \mathrm{~K}$. J. Phys. Chem. B 2013, 117, 2872-2877.

11. Sevilla, M.D.; D’Arcy, J.B.; Morehouse, K.M. An electron spin resonance study of gamma-irradiated frozen aqueous solutions containing N-acetylamino acids. J. Phys. Chem. 1979, 83, 2893-2897.

12. Laroff, G.P.; Fessenden, R.W. Equilibrium and kinetics of the acid dissociation of several hydroxyl alkyl radicals. J. Phys. Chem. 1973, 77, 1283-1288.

13. Sevilla, M.D.; Suryanarayana, D.; Morehouse, K.M. An ESR study of DNA base cation radicals produced by attack of oxidizing radicals. J. Phys. Chem. 1981, 85, 1027-1031.

14. Adhikary, A.; Kumar, A.; Heizer, A.N.; Palmer, B.J.; Pottiboyina, V.; Liang, Y.; Wnuk, S.F.; Sevilla, M.D. Hydroxyl ion addition to one-electron oxidized thymine: Unimolecular interconversion of C5 to C6 OH-adducts. J. Am. Chem. Soc. 2013, 135, 3121-3135.

15. Suryanarayana, D.; Sevilla, M.D. Electron spin resonance studies of barriers to hindered rotation in acetic acid, acetamide, and peptide radicals. J. Phys. Chem. 1979, 83, 1323-1327.

16. Suryanarayana, D.; Sevilla, M.D. INDO study of the anion radicals of acetic acid and acetamide. Nonplanarity and barriers to methyl group rotation. J. Phys. Chem. 1980, 84, 3045-3049. 
17. Fox, M.A.; Whitesell, J.K. Organic Chemistry, 3rd ed.; Jones and Bartlett Publishers: Sudbury, MA, USA, 2004; p. 295.

18. Adhikary, A.; Malkhasian, A.Y.S.; Collins, S.; Koppen, J.; Becker, D.; Sevilla, M.D. UVA-visible photo-excitation of guanine radical cations produces sugar radicals in DNA and model structures. Nucleic Acids Res. 2005, 33, 5553-5564.

19. Adhikary, A.; Kumar, A.; Becker, D.; Sevilla, M.D. The guanine cation radical: Investigation of deprotonation states by ESR and DFT. J. Phys. Chem. B. 2006, 110, 24171-24180.

20. Adhikary, A.; Khanduri, D.; Sevilla, M.D. Direct observation of the protonation state and hole localization site in DNA-oligomers. J. Am. Chem. Soc. 2009, 131, 8614-8619.

21. Westheimer, F.H. The magnitude of the primary kinetic isotope effect for compounds of hydrogen and deuterium. Chem. Rev. 1961, 61, 265-273.

22. Raiti, M.J.; Sevilla, M.D. Density Functional Theory investigation of the electronic structure and spin density distribution in peroxyl radicals. J. Phys. Chem. A 1999, 103, 1619-1626.

23. Frisch, M.J.; Trucks, G.W.; Schlegel, H.B.; Scuseria, G.E.; Robb, M.A.; Cheeseman, J.R.; Scalmani, G.; Barone, V.; Mennucci, B.; Petersson, G.A.; et al. Gaussian 09; Gaussian, Inc.: Wallingford, CT, USA, 2009.

24. SPARTAN, version 10; Wavefunction, Inc.: Irvine, CA, USA, 2010.

Sample Availability: Samples of the compounds employed are commercially available (see materials and methods for sources).

(C) 2014 by the authors; licensee MDPI, Basel, Switzerland. This article is an open access article distributed under the terms and conditions of the Creative Commons Attribution license (http://creativecommons.org/licenses/by/3.0/). 